\title{
Article \\ Evaluation of Dental Surface after De-Bonding Orthodontic Bracket Bonded with a Novel Fluorescent Composite: In Vitro Comparative Study
}

\author{
Marco Farronato ${ }^{1, *(\mathbb{D}}$, Davide Farronato ${ }^{2} \mathbb{D}$, Francesco Inchingolo ${ }^{3} \mathbb{D}$, Laura Grassi ${ }^{1}$, Valentina Lanteri ${ }^{1,4} \mathbb{D}^{\mathbb{D}}$ \\ and Cinzia Maspero ${ }^{1,4}(\mathbb{D}$ \\ 1 Department of Biomedical, Surgical and Dental Sciences, School of Dentistry, University of Milan, \\ 20100 Milan, Italy; laura.grassi@unimi.it (L.G.); valentina.lanteri@unimi.it (V.L.); \\ cinzia.maspero@unimi.it (C.M.) \\ 2 Department of Medicine and Surgery, Insubria University, 21100 Varese, Italy; davide.farronato@uninsubria.it \\ 3 Medicine Interdisciplinary Department, “Aldo Moro” University of Bari, 70121 Bari, Italy; \\ francesco.inchingolo@uniba.it \\ 4 Fondazione IRCCS Cà Granda, Ospedale Maggiore Policlinico, 20100 Milan, Italy \\ * Correspondence: marco.farronato@unimi.it; Tel.: +39-024693807
}

check for updates

Citation: Farronato, M.; Farronato, D.; Inchingolo, F.; Grassi, L.; Lanteri, V.; Maspero, C. Evaluation of Dental Surface after De-Bonding Orthodontic Bracket Bonded with a Novel Fluorescent Composite: In Vitro Comparative Study. Appl. Sci. 2021, 11, 6354. https://doi.org/ 10.3390/app11146354

Academic Editor: Vittorio Checchi

Received: 6 June 2021

Accepted: 2 July 2021

Published: 9 July 2021

Publisher's Note: MDPI stays neutral with regard to jurisdictional claims in published maps and institutional affiliations.

Copyright: (c) 2021 by the authors. Licensee MDPI, Basel, Switzerland. This article is an open access article distributed under the terms and conditions of the Creative Commons Attribution (CC BY) license (https:// creativecommons.org/licenses/by/ $4.0 /)$.
Abstract: The use of a new fluorescent composite can reduce some of the problems related to procedures of de-bonding orthodontic bracket (enamel damage, dentine lesions, and composite residuals). The aim of the presented study was to compare the effect of fluorescent and conventional non-fluorescent composite on dental surface and composite remnants by in vitro de-bonding tests. De-bonding of florescent composite (DFC) and the de-bonding of standard composite (DSC) were performed by operators on an in vitro sample of 48 teeth under UV light (360-370 $\mathrm{nm}$ min $20 \mathrm{~mW} / \mathrm{cm}^{2}$ ). Modified ARI (Adhesive Remnant Index), scored under 5.0×/235 magnification, was used for evaluation of dental surface after the procedure, and the duration required for de-bonding was measured. Significant differences in ARI between the two groups were observed (Pearson two-tailed $p=0.0061 .4 \pm 0.195 \%$ C.I.), and the average duration of de-bonding was $38 \mathrm{~s}$ (DFC) and $77 \mathrm{~s}$ (DSC) per tooth, respectively (Mann-Whitney test $p=0.015 ; 57.7 \pm 19.9$ 95\% C.I.). The use of fluorescent composite could significantly improve the quality of de-bonding by reducing the quantity of composite residuals and visible enamel damage, while reducing time needed for successful procedure performance.

Keywords: composite; fluorescence; de-bonding; residuals; enamel damage; orthodontics

\section{Introduction}

Composite removal is a crucial step at the end of the orthodontic treatment. This procedure is fundamental to restore the functional and macroscopic aesthetic appearance; if not performed correctly, it may leads to iatrogenic damages of healthy teeth and to negative clinical outcomes such as dental sensitivity, unaesthetic enamel damage, dentine lesions, and the presence of composite residuals [1-3].

Operators lacking experience are more likely to be facing the mentioned negative outcomes related to the adhesive and composite clean-up. Additionally, altered or abnormal dental anatomy can increase the difficulty of adhesive residual removal during the clean-up. Thus, it is extremely important to remove the adhesive without modifying the enamel surface with the aim to restore the original tooth appearance.

Several conventional methods are described in the literature to remove the adhesives and to polish the enamel [4]. The standard method of composite residual removal is the use of appropriate bur along with polishing discs and polishing paste. Ultrasonic devices and air-abrasion with aluminum oxide or other particles are an alternative. In addition, small loads of low-level laser irradiation applied during the bracket removal can eliminate 
most of the composite residuals on the enamel surface. However, in most cases, adhesive residuals are present on the enamel surface even after cleaning and polishing with rotary instruments [5].

A simplified de-bonding technique using a novel fluorescent composite and UV lamp was proposed. The method may significantly decrease the presence of the composite residuals, along with the risks related to the standard practice. BrackFix ${ }^{\circledR}$ composite (Voco $\mathrm{GmbH}$, Cuxhaven, Germany) has fluorescent properties due to fluorescent dye mixed with the composite base. This characteristic allows the compound materials used to react under UV light and to become easily detectable. The aim of the study was to evaluate the efficacy of a novel type and simplified de-bonding procedure of fluorescent adhesive composite for orthodontic brackets and to critically analyze its advantages in comparison to the standard composite during the procedures of composite clean-up. We hypothesized that this new product could reduce the operator-depending factor and, therefore, can increase de-bonding safety and quality.

\section{Materials and Methods}

A study protocol was designed in accordance with CRIS (Checklist for Reporting Invitro Studies) Guidelines [6]. The protocol described the procedures of the study, including the background, rationale, personnel, and institutions involved; data gathering; data management; specimen storage; materials and equipment; addressing potential bias; and defining the research and its aims.

Storage and utilization of used materials were in accordance with recommendations provided by the manufacturers. The study has been approved by the Ethics Committee of the University of Milan, Italy (protocol n. 314), and written consent for the use of extracted teeth was obtained from each patient.

De-bonding of BrackFix ${ }^{\circledR}$ (Voco GmbH, Cuxhaven, Germany) composite under UV light was compared to the conventional de-bonding method in a blind randomized in vitro test (Figures 1-3). Procedures were performed by postgraduate doctors with similar experience of de-bonding and by experienced operators. To investigate the efficacy of the novel composite, the dental surface after the de-bonding was evaluated by a single experienced operator.

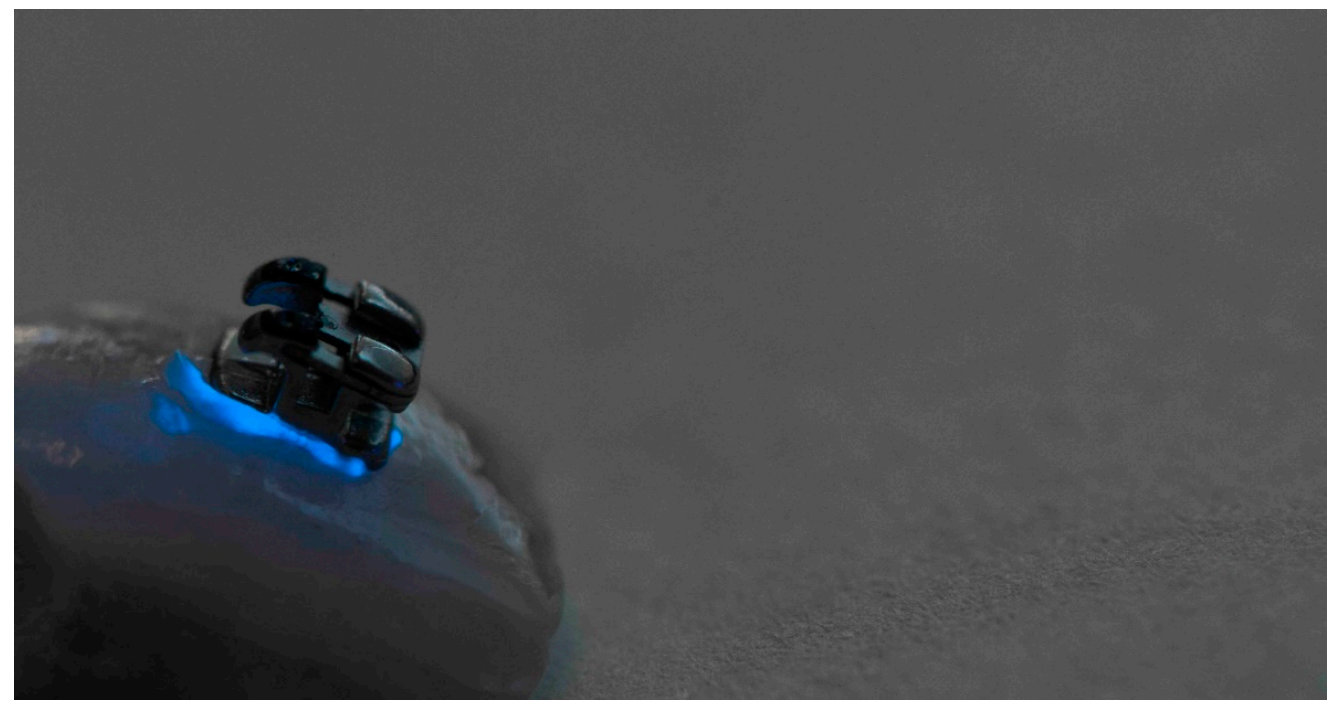

Figure 1. Bracket and composite observed under UV light (360-370 nm $\left.20 \mathrm{~mW} / \mathrm{cm}^{2}\right)$. 


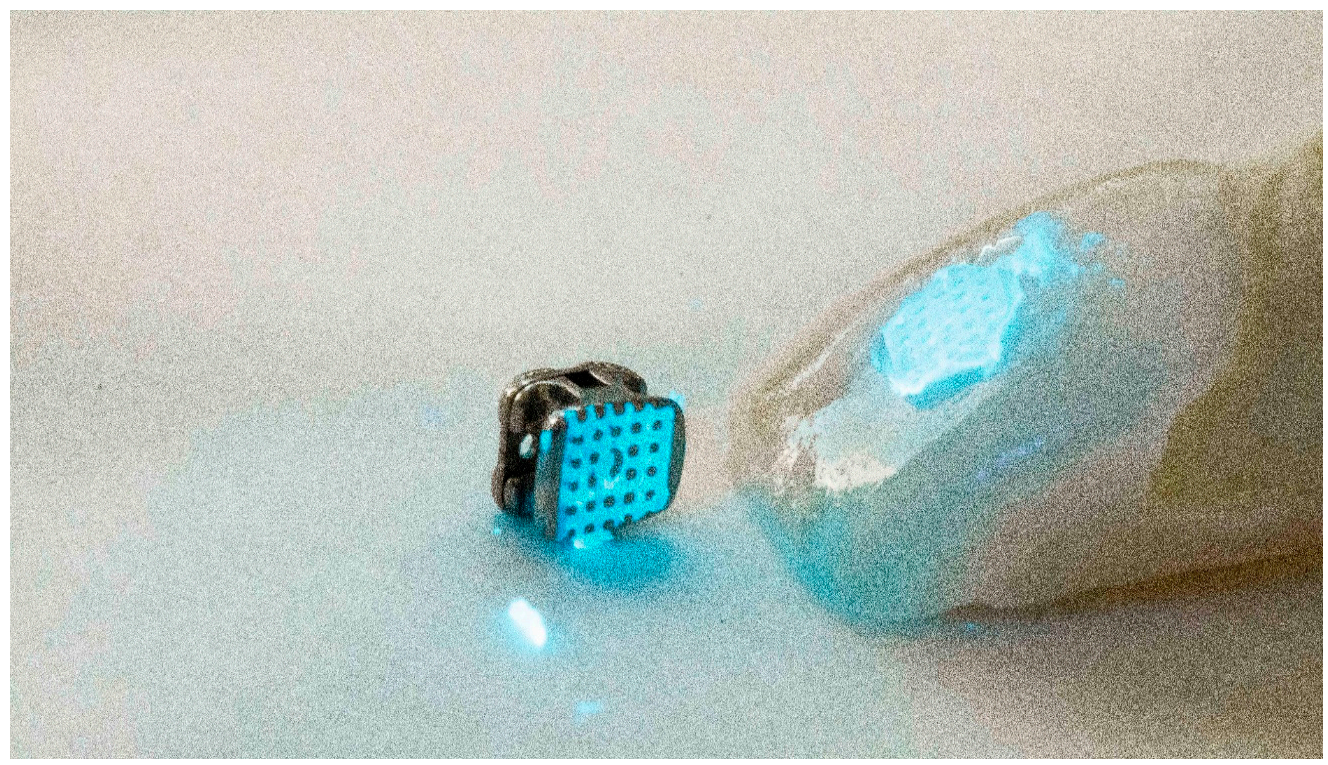

Figure 2. Bracket removal under UV light $360-370 \mathrm{~nm} 20 \mathrm{~mW} / \mathrm{cm}^{2}$.

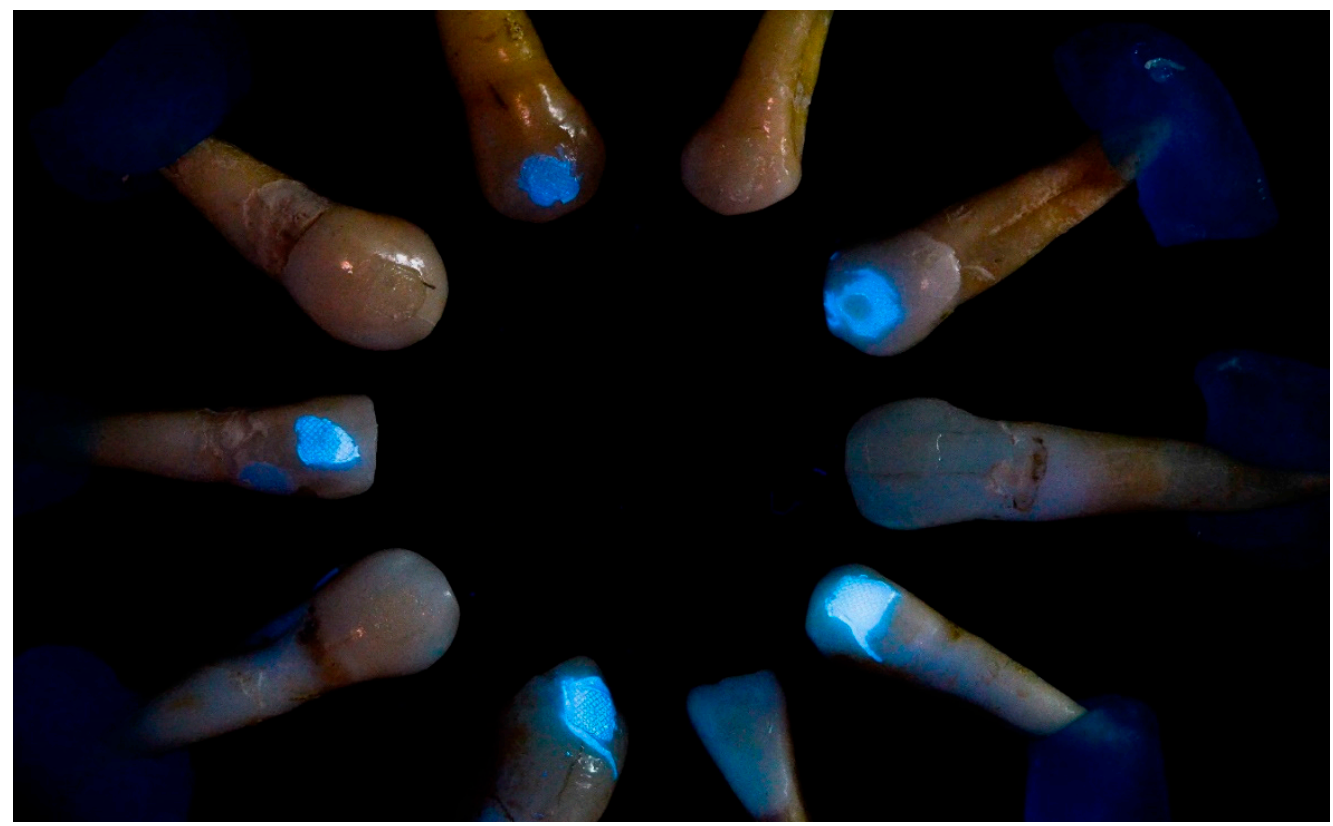

Figure 3. Visibility of Composite in two study groups under UV light (360-370 nm $\left.20 \mathrm{~mW} / \mathrm{cm}^{2}\right)$.

Operators involved in the study were recruited from the same postgraduate class, from the University of Milan, Italy, with no vision problems. The operators were randomly chosen to perform two types of de-bonding on two different extracted human teeth, the tests were also performed with experienced operators from the same institution. Each of them executed both the new de-bonding procedure of fluorescent composite (DFC) and "standard" de-bonding of non-fluorescent composite (DSC) in randomized, blinded order.

The sample consisted of 48 human teeth, extracted for various reasons. Inclusion criteria were as follows: good preservation state, integrity, absence of caries, no prior exposure to chemical agents, absence of extraction force generated cracks, and low levels or absence of demineralization. Teeth with minor cracks and small spots of demineralization were included as they are useful for the operator to evaluate enamel integrity in the process of adhesive clean-up. Such cases can be randomly found in patients undergoing or finishing orthodontic therapy. Exclusion criteria included: major cracks, lesions or dental 
restorations, anatomical abnormalities, or extraction signs on the crown. The sample of 48 human teeth included all teeth types in equal proportions-10 incisors, 10 canines, 14 premolars, and 14 molars. During all procedures, teeth were stored in isotonic solution at $4{ }^{\circ} \mathrm{C}$ with the solution being changed daily for a maximum of 5 days. All the teeth were selected and the inclusion/exclusion criteria were evaluated by an experienced operator prior to the study.

The teeth were etched with 37\% phosphoric acid gel (Vococid, Voco GmbH, Cuxhaven, Germany) for $30 \mathrm{~s}$, rinsed with water, and air-dried as recommended by the manufacturer. Stainless-steel brackets (Leone S.p.A, Sesto FiorentinoItaly) were applied to the teeth by a single operator according to manufacturer instructions. Composites (fluorescent and standard) were applied in similar quantities and cured with a light-curing unit with a brightness of at least $1000 \mathrm{~mW} / \mathrm{cm}^{3}$ for $20 \mathrm{~s}$. The novel Composite BrackFix ${ }^{\circledR}$ (Voco GmbH, Cuxhaven, Germany) was used for the DFC group. BrackFix ${ }^{\circledR}$ primer (Voco GmbH, Cuxhaven, Germany) was applied before application of the composite BrackFix ${ }^{\circledR}$. Fluorescent dye added to the composite base of BrackFix ${ }^{\circledR}$ allows it to be detectable and seen under the UV light (Figures 1-3). The control group (DSC) was bonded under similar conditions using a non-fluorescent composite Transbond XT (3M, Saint Paul, MN, USA).

Teeth were numbered and classified, and 24 teeth pairs were randomly assigned. Each Operator was given one teeth pair embedded in an acrylic resin block consisting of one tooth from the DSC and one from the DFC group, de-bonding instruments, and instructions to remove brackets and composite using orthodontic de-bonding pliers under assistance (aspiration of the residuals and holding of the UV lamp). The scopes of the research were blinded so the operators performed the de-bonding without knowing the effects of the UV lamp used on the composite of both DFC and DSC. The use of UV light to evidence the presence of composite remnants, even without fluorescent particles, has previously been evidenced as a positive outcome factor in past research [7-11]; therefore, blinding was necessary to avoid bias. The UV lamp used in the study had the following characteristics: $360-370 \mathrm{~nm}$ min $20 \mathrm{~mW} / \mathrm{cm}^{2}$ (which is harmless for biological tissues but requires eyes protection). It was held a maximum of $50 \mathrm{~cm}$ from the tooth in order not to dissipate the light and not to be in contrast with the environmental light to decrease potential risk of bias of light change due to different times of the day and weather conditions. Operators wore protective eyeglasses to avoid damage related to the use of UV light.

The simplified de-bonding procedure was performed and composite was removed with the aid of a 12-flute tungsten carbide bur under UV lamp. The procedure was performed under the same conditions for both teeth from the two sample groups. The duration of the removal was measured for a subgroup of 20 teeth with similar anatomic structures (canines and incisors) right after the removal of the orthodontic bracket at the start of the removal with burs performed by similarly experienced operators. The duration of the procedure was measured only for a subgroup $(n=20)$ of frontal teeth with similar anatomy (10 incisors and 10 canines) to decrease the risk of bias related to the anatomical variance (Figure 4 ).

- Grade 0: visible composite residuals OR significant damage to the enamel surface visible without $5 \times$ magnification from any view $\mathrm{OR}$ any anatomical change to the tooth;

- Grade 1: minor enamel scratching or damage not exposing the dentine, which was partially visible without $5 \times$ magnification from some views or/and composite residuals visible using $5 \times$ magnification only;

- Grade 2: absence of scratches or presence of minor scratches in the enamel surface, visible only with the use of $5 \times$ magnification.

All the collected data were analyzed using statistical software (SPSS 20, IBM) by calculation of descriptive statistics and Pearson Two-Tailed test, and Mann-Whitney $U$ tests (independent samples) for small sample sizes were used for group comparison of ARI and duration of procedure; $p$-value $<0.05$ was considered statistically significant (Figure 5). 


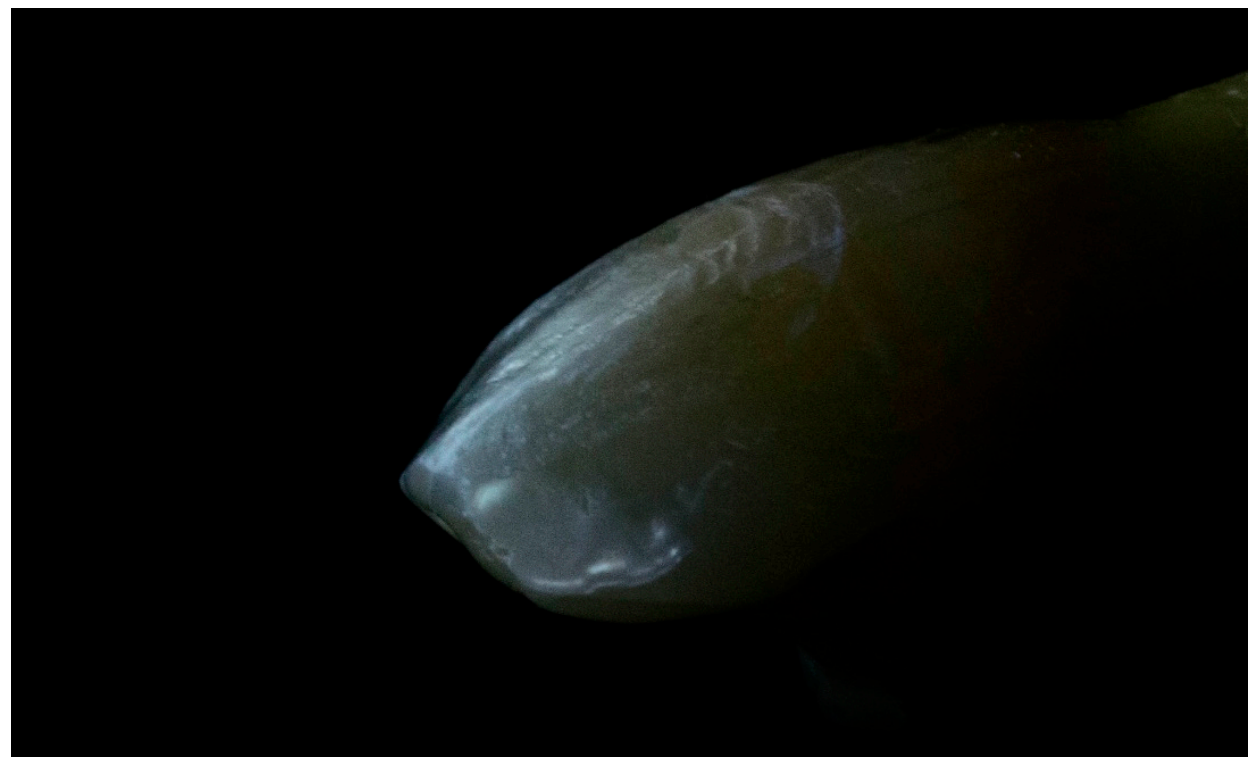

Figure 4. After de-bonding tooth surface. After the de-bonding, all the teeth were grouped, and de-bonding was evaluated by a blinded single operator. Each tooth was classified using a modified ARI (Adhesive Remnant Index) scale from 0 to 2 with the use of $5.0 \times / 235$ telescopic head-worn magnifier as follows.

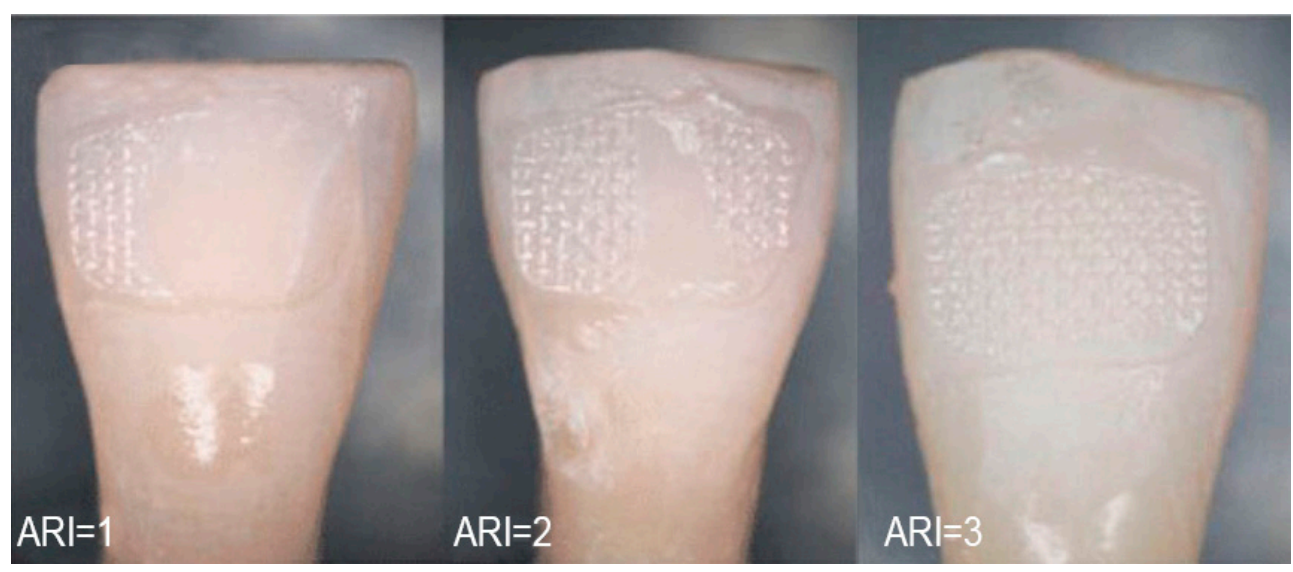

Figure 5. Illustration of Adhesive Remnant Index (ARI): ARI 0, no adhesive on the tooth; ARI 1, less than $1 / 2$ adhesive on the tooth; ARI 2, more than $1 / 2$ of the adhesive on the tooth; ARI 3 , all of the adhesive on the tooth.

\section{Results}

All the operators performing de-bonding procedures with fluorescent composite found the use of this novel composite easier and therefore faster in comparison to the conventional composite used in the DSC group. The mean duration of composite removal in the DFC group (visible under UV light) was $38 \mathrm{~s}$, and for the DSC group (conventional composite) it was $77 \mathrm{~s}$ (Table 1). The differences in the duration was significant (MannWhitney test $p=0.01557 .7 \pm 19.995 \%$ C.I.) under the study conditions. 
Table 1. Duration of de-bonding among similarly experienced operators and similar anatomy dental elements.

\begin{tabular}{ccc}
\hline & DFC & DSC \\
\hline Operator \#1 & $40 \mathrm{~s}$ & $234 \mathrm{~s}$ \\
\hline Operator \#2 & $60 \mathrm{~s}$ & $87 \mathrm{~s}$ \\
\hline Operator \#3 & $36 \mathrm{~s}$ & $54 \mathrm{~s}$ \\
\hline Operator \#4 & $23 \mathrm{~s}$ & $56 \mathrm{~s}$ \\
\hline Operator \#5 & $17 \mathrm{~s}$ & $31 \mathrm{~s}$ \\
\hline Operator \#6 & $37 \mathrm{~s}$ & $67 \mathrm{~s}$ \\
\hline Operator \#7 & $40 \mathrm{~s}$ & $80 \mathrm{~s}$ \\
\hline Operator \#8 & $53 \mathrm{~s}$ & $27 \mathrm{~s}$ \\
\hline Operator \#9 & $37 \mathrm{~s}$ & $69 \mathrm{~s}$ \\
\hline Operator \#10 & $41 \mathrm{~s}$ & $66 \mathrm{~s}$ \\
\hline SD & 12.4 & 58.3 \\
\hline mean & $38 \mathrm{~s}$ & $77 \mathrm{~s}$ \\
\hline maximum & $60 \mathrm{~s}$ & $234 \mathrm{~s}$ \\
\hline minimum & $17 \mathrm{~s}$ & $27 \mathrm{~s}$ \\
\hline Mann-Whitney & $p=0.015$ & \\
\hline 95\% C.I. & 19.9 & \\
\hline
\end{tabular}

Significant differences were also observed in the ARI evaluation $(p=0.006$, Pearson Two-Tailed $1.4 \pm 0.1$ 95\% C.I.). In the DSC group, $16.7 \%$ (4 from 24 ) of teeth were assessed as Grade 0; $50 \%$ (12 from 24) as Grade 1; and 33.3\% (8 from 24) as Grade 2. In the DFC group, no tooth was evaluated as Grade 0; $33.3 \%$ (8 from 24 ) were evaluated as Grade 1; and $66.6 \%$ (16 from 24 ) as Grade 2 (Table 2).

Table 2. Modified ARI evaluation.

\begin{tabular}{|c|c|c|c|}
\hline \multirow{2}{*}{ Operator } & \multicolumn{2}{|c|}{ A.R.I Grade } & \multirow{2}{*}{ Grades Description } \\
\hline & DFC & DSC & \\
\hline Operator \#1 & 2 & 1 & $\begin{array}{l}0 \text { grade: visible composite remnants OR significant damage to the } \\
\text { enamel surface visible without loupes } 5 \times \text { from any projection of } \\
\text { the observer OR any anatomical change to the tooth. }\end{array}$ \\
\hline Operator \#2 & 1 & 1 & $\begin{array}{c}1 \text { grade: minor enamel scratching or damage with no exposition of } \\
\text { the dentine partially visible without loupes } 5 \times \text { from a limited } \\
\text { number of visible projections of the observer or } / \text { and composite } \\
\text { remnants visible with loupes } 5 \times \text { only. }\end{array}$ \\
\hline Operator \#3 & 2 & 1 & $\begin{array}{l}2 \text { grade: absence or presence of minor scratches to the enamel } \\
\text { surface visible only with the use of head-worn loupe } 5 \times \text {. }\end{array}$ \\
\hline Operator \#4 & 2 & 0 & \\
\hline Operator \#5 & 2 & 0 & \\
\hline Operator \#6 & 2 & 1 & \\
\hline Operator \#7 & 2 & 2 & \\
\hline Operator \#8 & 2 & 2 & \\
\hline Operator \#9 & 1 & 2 & \\
\hline Operator \#10 & 2 & 1 & \\
\hline
\end{tabular}


Table 2. Cont.

\begin{tabular}{|c|c|c|c|}
\hline \multirow{2}{*}{ Operator } & \multicolumn{2}{|c|}{ A.R.I Grade } & \multirow{2}{*}{ Grades Description } \\
\hline & DFC & DSC & \\
\hline Operator \#11 & 2 & 2 & \\
\hline Operator \#12 & 1 & 1 & \\
\hline Operator \#13 & 1 & 1 & \\
\hline Operator \#14 & 2 & 2 & \\
\hline Operator \#15 & 1 & 1 & \\
\hline Operator \#16 & 2 & 0 & \\
\hline Operator \#17 & 2 & 2 & \\
\hline Operator \#18 & 1 & 1 & \\
\hline Operator \#19 & 1 & 1 & \\
\hline Operator \#20 & 1 & 0 & \\
\hline experienced op & 2 & 1 & \\
\hline experienced op & 2 & 1 & \\
\hline experienced op & 2 & 2 & \\
\hline experienced op & 2 & 2 & \\
\hline st. dev. & 0.48 & 0.70 & \\
\hline average & 1.67 & 1.17 & \\
\hline MAX & 2 & 2 & \\
\hline MIN & 1 & 0 & \\
\hline Pearson & $p=0.006$ & & \\
\hline 95\% C.I. & 0.182997 & & \\
\hline
\end{tabular}

\section{Discussion}

As recently described in the literature, the operator's experience during the debonding procedure affects the quality of the results [1-3,5,7-10]. The design of the proposed study also involved inexperienced operators. Each of the postgraduate doctors was instructed in a pre-operative session by experienced operators. This study design was chosen to minimize bias related to high experience of the operators, and also to permit repetitiveness of the test under the same conditions (by having the same experience levels) and compared to experienced professionaly.

Likewise, all procedures were done under the same lighting conditions due to the fact that changing weather and changing lighting can highly affect and compromise the reproducibility of the work. In fact, no direct sunlight was affecting the study, and the UV light was held at a minimum distance of $50 \mathrm{~cm}$ in both groups. This allowed the composite to have the same optical reaction during all de-bonding procedures. UV light was used under the same conditions during the DSC procedure to discard UV advantages not related to the fluorescent characteristics of the novel fluorescent composite, as described by Ribeiro et al. [11].

Montasser et al. demonstrated that ARI grades are significantly different when testing is carried out with the naked eye and 10-20× magnification; but they are similar when using $10 \times$ magnification and naked-eye evaluation [12]. The evaluation was carried out using grade scale 0 to 2 of the modified ARI. Originally, 4 grades of ARI were described by Årtun et al., or alternatively modified 5 grades by Bishara et al. [13,14]. In our study, the ARI grades were modified specifically for the purpose of macroscopic evaluationTherefore, the use of magnifying glasses can be fundamental in the phase of bracket placement and cleaning of excess composite during bonding. However, the use of Adhesive Remnant 
Index remains a controversial topic [1]. Other authors evaluated the assessment of the confidence of ARI score with other methods such as photography, use of the naked eye, and $20 \times$ magnifications, resulting in no significant differences [15-23].

The simplified grades of ARI provided the teeth evaluation with a simplified procedure and less risk of bias [8,12-14].

Recently, new de-bonding techniques were developed, or existing methods were improved, for example, Taha et al. proposed the use of a novel bioactive glass via air abrasion $[22,24,25]$.

Currently, no technique has proven to be capable of complete and efficient removal of residual adhesives without inducing even a minor amount of enamel damage [5].

The new methodology using UV light and UV florescent composite might improve the safety and decrease the iatrogenic damage of the enamel and dentine during the clean-up processes after de-bonding in the future. It might result in an improvement in the health for all patients undergoing orthodontic treatment due to the decrease of macroscopic composite residuals, which could decrease plaque retention, even though it is not a resolutive procedure. The restoration of patient's pre-treatment dental health is a priority to every orthodontic procedure, and more efforts should be made to help the clinician as well as to develop effective protocols. We can also speculate that recent advancements and popularity in clear aligners could benefit from the same technology during attachment removals [26]. The duration of the procedure is also important during this kind of procedure. The new methodology seems to highly decrease the time required to effectively remove the composite, probably because the composite remnant's magnitude and position can be recognized easily and faster due to their strong fluorescent proprieties and bright color. The main limitation of the study is that the results produced should be tested on a larger sample, and would be even better if carried out in vivo. Further in vivo studies with professionals are needed to determine if this new method requires less operating time.

Due to the nature of the study, polishing and clean-up procedures were excluded as, rarely, they can produce harm to enamel tissue; therefore, they were considered out of the scope of the research. It should, however, be considered that the ARI can be affected by this last phase.

\section{Conclusions}

This study suggests that the aid of UV lamps and the use of fluorescent composite might decrease macroscopic composite residuals and visible scratches after de-bonding procedures performed by postgraduate doctors. The de-bonding procedure is faster under the study circumstances. Further in vivo and larger sample studies are needed.

Author Contributions: Conceptualization, M.F. and F.I.; methodology, D.F.; software, L.G.; validation, V.L.; formal analysis, F.I.; investigation, L.G.; resources, C.M.; data curation, M.F. and D.F.; writing-original draft preparation, V.L. and C.M.; supervision, V.L.; project administration, M.F.; funding acquisition, D.F. All authors have read and agreed to the published version of the manuscript.

Funding: This research received no external funding.

Institutional Review Board Statement: The study was conducted according to the guidelines of the Declaration of Helsinki and approved by the Institutional Review Board (or Ethics Committee) of University of Milan, Italy. Protocol number 314.

Informed Consent Statement: Informed consent was obtained from all subjects involved in the study.

Data Availability Statement: Supplementary data will be made available by the official institution (www.unimi.it) (accessed on 10 May 2021).

Acknowledgments: The study was carried out without any commitment or financial support from the manufacturing company Voco GmbH, Cuxhaven, Germany. The University of Milan requested samples without any personal or institutional interest or expenses. The company kindly provided the material without having any prior information about the prepared study: Composite: BrackFix 
(Voco GmbH, Cuxhaven, Germany); UV lamp 360-370 nm 20 mW/ cm²; Etching: Vococid (Voco $\mathrm{GmbH}, \mathrm{Cuxhaven,} \mathrm{Germany);} \mathrm{Primer:} \mathrm{Brackfix} \mathrm{primer} \mathrm{(Voco} \mathrm{GmbH,} \mathrm{Cuxhaven,} \mathrm{Germany).}$

Conflicts of Interest: The authors declare no conflict of interest.

\section{References}

1. Mohebi, S.; Shafiee, H.-A.; Ameli, N. Evaluation of enamel surface roughness after orthodontic bracket debonding with atomic force microscopy. Am. J. Orthod. Dentofac. Orthop. 2017, 151, 521-527. [CrossRef]

2. Bollen, C.M.; Lambrechts, P.; Quirynen, M. Comparison of surface roughness of oral hard materials to the threshold surface roughness for bacterial plaque retention: A review of the literature. Dent. Mater. 1997, 13, 258-269. [CrossRef]

3. Goel, A.; Singh, A.; Gupta, T.; Gambhir, R.S. Evaluation of surface roughness of enamel after various bonding and clean-up procedures on enamel bonded with three different bonding agents: An in-vitro study. J. Clin. Exp. Dent. 2017, 9, e608-e616. [CrossRef] [PubMed]

4. Attin, R.; Stawarczyk, B.; Kecik, D.; Knosel, M.; Wiechmann, D.; Attin, T. Shear bond strength of brackets to demineralize enamel after different pretreatment methods. Angle Orthod. 2012, 82, 56-61. [CrossRef] [PubMed]

5. Janiszewska-Olszowska, J.; Szatkiewicz, T.; Tomkowski, R.; Tandecka, K.; Grocholewicz, K. Effect of orthodontic debonding and adhesive removal on the enamel-current knowledge and future perspectives-A systematic review. Med. Sci. Monit. Basic Res. 2014, 20, 1991-2001.

6. Krithikadatta, J.; Gopikrishna, V.; Datta, M. CRIS Guidelines (Checklist for Reporting In-vitro Studies): A concept note on the need for standardized guidelines for improving quality and transparency in reporting in-vitro studies in experimental dental research. J. Conserv. Dent. 2014, 17, 301-304. [CrossRef] [PubMed]

7. Fan, X.-C.; Chen, L.; Huang, X.-F. Effects of various debonding and adhesive clearance methods on enamel surface: An in vitro study. BMC Oral Health 2017, 17, 58. [CrossRef] [PubMed]

8. Kim, S.-S.; Park, W.-K.; Son, W.-S.; Ahn, H.-S.; Ro, J.-H.; Kim, Y.-D. Enamel surface evaluation after removal of orthodontic composite remnants by intraoral sandblasting: A 3-dimensional surface profilometry study. Am. J. Orthod. Dentofac. Orthop. 2007, 132, 71-76. [CrossRef] [PubMed]

9. Maspero, C.; Giannini, L.; Galbiati, G.; Nolet, F.; Esposito, L.; Farronato, G. Titanium orthodontic appliances for allergic patients. Minerva Stomatol. 2014, 63, 403-410.

10. Dubey, C.; Prakash, A.; Sharma, A.; Jain, U. Enigma of Debonding. Orthod. J. Nepal 2016, 5, 37-41. [CrossRef]

11. Ribeiro, A.A.; Almeida, L.F.; Martins, L.P.; Martins, R.P. Assessing adhesive remnant removal and enamel damage with ultraviolet light: An in-vitro study. Am. J. Orthod. Dentofac. Orthop. 2017, 151, 292-296. [CrossRef]

12. Montasser, M.A.; Drummond, J.L. Reliability of the adhesive remnant index score system with different magnifications. Angle Orthod. 2009, 79, 773-776. [CrossRef] [PubMed]

13. Årtun, J.; Bergland, S. Clinical trials with crystal growth conditioning as an alternative to acid-etch enamel pretreatment. Am. J. Orthod. Dentofac. Orthop. 1984, 85, 333-340. [CrossRef]

14. Bishara, S.E.; Trulove, T.S. Comparisons of different debonding techniques for ceramic brackets: An in vitro study. Am. J. Orthod. Dentofac. Orthop. 1990, 98, 145-153. [CrossRef]

15. Oz, A.A.; Yazicioglu, S.; Arici, N.; Akdeniz, B.S.; Murat, N.; Arıcı, S. Assessment of the Confidence of the Adhesive Remnant Index Score with Different Methods. Turk. J. Orthod. 2014, 26, 149-153. [CrossRef]

16. Cehreli, S.B.; Polat-Ozsoy, O.; Sar, C.; Cubukcu, H.E. A comparative study of qualitative and quantitative methods for the assessment of adhesive remnant after bracket debonding. Eur. J. Orthod. 2011, 34, 188-192. [CrossRef] [PubMed]

17. Arima, S.; Namura, Y.; Tamura, T.; Shimizu, N. Easy Debonding of Ceramic Brackets Bonded with a Light-Cured Orthodontic Adhesive Containing Microcapsules with a $\mathrm{CO}_{2}$ Laser. Photomed. Laser Surg. 2018, 36, 162-168. [CrossRef]

18. Dumbryte, I.; Linkeviciene, L.; Linkevicius, T.; Malinauskas, M. Does orthodontic debonding lead to tooth sensitivity? Comparison of teeth with and without visible enamel microcracks. Am. J. Orthod. Dentofac. Orthop. 2017, 151, 284-291. [CrossRef] [PubMed]

19. D'Apuzzo, F.; Perillo, L.; Delfino, I.; Portaccio, M. Monitoring early phases of orthodontic treatment by means of Raman spectroscopies. J. Biomed. Opt. 2017, 22, 1-10. [CrossRef] [PubMed]

20. Grassia, V.; Gentile, E.; Di Stasio, D.; Jamilian, A.; Matarese, G.; D'Apuzzo, F.; Lucchese, A. In vivo confocal microscopy analysis of enamel defects after orthodontic treatment: A preliminary study. Ultrastruct. Pathol. 2016, 40, 317-323. [CrossRef]

21. Farronato, G.; Giannini, L.; Galbiati, G.; Cannalire, P.; Martinelli, G.; Tubertini, I.; Maspero, C. Oral tissues and orthodontic treatment: Common side effects. Minerva Stomatol. 2013, 62, 431-446. [PubMed]

22. Taha, A.; Hill, R.G.; Fleming, P.S.; Patel, M.P. Development of a novel bioactive glass for air-abrasion to selectively remove orthodontic adhesives. Clin. Oral Investig. 2017, 22, 1839-1849. [CrossRef] [PubMed]

23. Farronato, M.; Maspero, C.; Lanteri, V.; Fama, A.; Ferrati, F.; Pettenuzzo, A.; Farronato, D. Current state of the art in the use of augmented reality in dentistry: A systematic review of the literature. BMC Oral Health 2019, 19, 1-15. [CrossRef]

24. Ferreira, J.T.L.; Borsatto, M.C.; Saraiva, M.C.P.; Matsumoto, M.A.N.; Torres, C.P.; Romano, F.L. Evaluation of Enamel Roughness in Vitro After Orthodontic Bracket Debonding Using Different Methods of Residual Adhesive Removal. Turk. J. Orthod. 2020, 33, 43-51. [CrossRef] 
25. Pinho, M.; Manso, M.C.; Almeida, R.F.; Martin, C.; Carvalho, O.; Henriques, B.; Silva, F.; Ferreira, A.P.; Souza, J.C.M. Bond Strength of Metallic or Ceramic Orthodontic Brackets to Enamel, Acrylic, or Porcelain Surfaces. Materials 2020, 13, 5197. [CrossRef]

26. Tartaglia, G.; Mapelli, A.; Maspero, C.; Santaniello, T.; Serafin, M.; Farronato, M.; Caprioglio, A. Direct 3D Printing of Clear Orthodontic Aligners: Current State and Future Possibilities. Materials 2021, 14, 1799. [CrossRef] [PubMed] 